\title{
A Comparative Investigation into The Effects of Party-System Variables on Party Switching using Individual-Level Data
}

Party Politics, accepted.

\begin{abstract}
Previous comparative electoral studies using aggregate data indicate the importance of partysystem variables, such as polarization and the number of parties, with regard to the level of volatility between two elections. Research using individual level data has shown elements, such as political knowledge, political disaffection and party identification, explain why voters remained faithful to their party or not. Until now, no study has investigated these variables simultaneously on individual level data using a large set of elections. This study fills that important gap in the literature using data from 29,591 voters in 33 elections. We find polarization influences party-switching at the individual level, rather than the sheer number of parties, as aggregate-level analyses suggest.
\end{abstract}




\section{Introduction}

Until the end of the 1970's electoral research focused on personal characteristics and the social environment of the citizen as determinants of the vote choice (Berelson et al., 1963; Campbell et al., 1963; Key, 1966; Lazarsfeld et al., 1949). It was not until 1979 that Pedersen drew attention to the effect of the political system on party switching, finding a clear link 'between the number of options open to the individual voter, and the voters' propensities to transfer votes between parties.' (Pedersen, 1979: 14). As an important limitation, Pedersen used only aggregate, country level, data of volatility to describe this individual-level phenomenon. Ever since, the standard research approach in this area examines party system characteristics and vote change at the aggregate level.

A number of assumptions have to made for inferences about the individual-level to be valid when using aggregate data of net volatility to investigate party switching. One of the key assumptions being that no single voter abstains from voting. If individual-level data are used, by contrast, we can focus only on those voters who voted in two consecutive elections. This should give a much more exact estimate of the effect of the party-system on party switching ${ }^{1}$.

Pedersen additionally assumed party switching is driven by the voters' perception of the average distance between parties when there are more of them, and not the number of parties by itself. Voters will be more likely to consider leaving the party they previously voted for as the number of ideologically proximate parties increases. Furthermore, Pedersen considered the interchangeability between the number of parties and polarization as a truism. Later

\footnotetext{
${ }^{1}$ In this article we distinguish between volatility, which refers to the total amount of change in electoral choice between two elections and party switching which only refers to voters that voted in two consecutive elections and voted for a different party at both occasions. Volatility includes switching between parties, but also between abstention and a vote for a party and vice-versa.
} 
empirical research, however, points out that the number of parties and polarization are best treated as distinct elements of a party system.

In this article, we assess whether the link between party switching and the characteristics of the party system is driven by individual-level dynamics and caused by polarization in the party system, or by the number of parties. We will, however, also take into account a number of individual level predictors of switching. To do this we use the data from the Comparative Study of Electoral Systems (CSES).

We start the paper with an overview of the literature on volatility and party switching, in which we highlight the contextual and individual causes of both concepts. Next we present the data and methods used for the analyses. After describing the results we end with some concluding remarks and caveats of the current paper.

\section{Literature}

In liberal democracies, political parties are the organized expression of ideological diversity in the political sphere (Ware, 1996). They are expected to place themselves at the most advantageous position in ideological space in order to maximize their potential electorate (Downs, 1957). As the seminal work of Lipset and Rokkan (1967) pointed out, several cleavages exist in western societies that strongly differentiate political parties. This cleavage structure causes voters to be strongly aligned to particular parties and a large section of society was said to be 'frozen' into these cleavages. But as Blondel (1968) pointed out, some electoral fluctuation is absolutely necessary to keep democratic systems structurally balanced. Identifying the voters who switch parties, therefore, became - and still is - a prominent field of study in political science. 
Several scholars have drawn attention to a trend of increasing electoral volatility since the late 1970s (Crewe and Denver, 1985; Dalton et al., 2002; Pedersen, 1979; Rose and Mcallister, 1986). This trend is considered an indication that the old ties between voters and parties have waned, resulting in 'dealignment'. The literature identifies the important role the party system plays in explaining party switching. Studies in this area often reference the relationship between party switching and either the number of parties, or the dispersion of the parties in an ideological issue space. Using data from 103 elections from 1945-1975, Pedersen found a clear link between the number of parties and net volatility. He explained this relationship with reference to polarization as the causal mechanism. Even though the theoretical mechanism was situated at the individual level, Pedersen could only find indications for it at an aggregate level. He therefore concluded his paper by saying that that his findings warranted further study with individual level data. So far no one has systematically tested the impact of these contextual variables at the individual level. We address this gap in the literature by means of a specific focus on the contextual causes of volatility and party switching by means of aggregate and individual-level data, respectively.

\subsection{The Political System}

The literature identifies two important structural features of a political system in relation to electoral party switching: the number of parties, on the one hand, and the ideological polarization of these parties, on the other.

These two concepts are generally considered to be closely related. More electoral parties are regularly considered synonymous with more polarization (Pedersen, 1979; Sartori, 2005). Crepaz (1990) initially found an empirical relationship between polarization and the number of parties, but using more refined data analyses it has been shown that the number of parties in and of itself is not indicative of more extreme positioning of parties (Budge and 
McDonald, 2006; Ezrow, 2008). Dalton and Anderson (2011) also found no significant correlation between the number of parties and polarization ${ }^{2}$ in their investigation using the large CSES dataset. It is therefore logical to treat them as two distinct contextual variables in this paper.

Considering the number of parties in a party-system, we would expect there to be a linear relationship between the number of parties and electoral party switching. The likelihood that a voter has an alternative to her previous choice that is worthy of her vote increases with the number of parties (Blais and Gschwend, 2010). While it might appear to be conventional wisdom that more parties foster party switching, not all research finds a significant effect of the number of parties on levels of party switching. Looking at newer democracies, some scholars are inconclusive about the effect of the number of parties on net volatility (Epperly, 2011; Roberts and Wibbels, 1999). Most of the available research, however, indicates a significantly more volatile system as the number of parties increases (Bartolini and Mair, 1990; Crewe and Denver, 1985; Lane and Ersson, 2007; Mainwaring and Zoco, 2007). The reason why most research still assumes more party switching in larger party systems, however, relates to ideological proximity rather than the number of options voters have per se (Tavits, 2005; Toka, 1998).

The degree of polarization in an electoral context is assumed to strongly affect party switching. There are a number of reasons for this theoretical expectation. First, one expectation in the literature is that polarization and party switching are inversely related. This logic is derived from the idea Downs (1957) defended in his Economic Theory of Democracy: if polarization is high, the ideological spacing between parties will increase,

\footnotetext{
${ }^{2}$ Even though we use a slightly different set of elections from the CSES compared to Dalton \& Anderson we also found no correlation between the effective number of electoral parties and polarization in our dataset (results available from the authors on request).
} 
making a switch less likely (Hazan, 1997). There is some indirect evidence supporting this idea. The correlation between a voter's placement on a left-right scale and the position of the party she votes for is significantly higher in more polarized elections (Dalton, 2008). This indicates that, when offered a more diverse set of options, voters will find a party closer to their own position and have less reason to switch. Similarly, the relation between selfplacement on a left-right scale and having a party-affiliation was found to be stronger in polarized party systems (Curini and Hino, 2012; Freire, 2008). The effect of ideological polarization on volatility has also been investigated at a macro-level. Typically,this has been done by controlling for the number of parties in a system. Tavits (2005: 286) for example makes the strong argument that in highly polarized systems "switching one's vote would mean trading one's ideology”. Both Roberts and Wibbels (1999) and Tavits (2005) find significant effects indicating that polarization decreases net volatility when controlling for the number of parties in a party system.

A second reason to assume volatility is reduced in strongly polarized systems can be found in the 'supply' side of the electoral spectrum. In highly polarized systems, parties are more likely to be organized around specific cleavages that are the basis of polarization itself (Mair, 1995). This might refrain parties from going into competition for certain parts of the electorate that are considered "unattainable" (Bardi and Mair, 2008). Conversely, as Mair (1995) contends, if parties lose their distinct profiles, they will end up fishing in the same broader pool of voters, and this makes it more likely that these voters will switch for more valence-based differences, such as a more attractive party leadership (Deegan-Krause and Enyedi, 2010; but see Vegetti, 2014).

Several scholars found a weak negative effect of polarization on volatility. All of them, however, used aggregate data which only allows a rudimentary estimation of gross volatility (Bartolini and Mair, 1990; Roberts and Wibbels, 1999; Tavits, 2005). The reasoning of 
theories about the effects of the number of parties and polarization however, is clearly at the individual level and relates to party switching. Testing these contextual theories by means of individual data can therefore be considered a prerequisite for understanding the mechanisms.

Following this review of the literature, the two contextual hypotheses that will be investigated in this paper are:

Hypothesis 1: An increasing number of parties will increase the probability of party switching Hypothesis 2: A higher level of polarization in the party system will decrease the probability of party switching.

\subsection{Individual-level controls}

Although the focus of this paper is on the influence of contextual level variables on party switching, it is important to take into consideration individual-level predictors of switching as well. In this regard, party identification is generally considered a crucial variable in voting behaviour research (Dalton, 2013) and in research on party switching more specifically. As an important vote choice heuristic, partisanship acts to stabilize voting behaviour (Lachat, 2007).

Furthermore, political sophistication is widely regarded to have an effect on party switching. The first survey-based research on what causes voters to switch parties concluded: 'Stability in vote is characteristic of those interested in politics and instability of those not particularly interested' (Berelson et al., 1963: 20). Scholars nowadays expect a curvilinear effect of 
political sophistication on party switching, with most switching among the middle sophisticated (Dassonneville and Dejaeghere, 2014; Kuhn, 2009; Lachat, 2007).

Finally, political attitudes are regularly included in models to understand what makes people switch votes. Scholars seem to agree that disaffection with politics is associated with volatility. With his 'frustrated floating voter hypothesis', Zelle (1995) drew attention to the fact that volatile voters are less satisfied with the political system and less trusting in politics. Switching parties should therefore be considered as a voter's manifestation of a mood of protest. Recent findings seem to confirm this pattern of disaffection leading to volatility for a number of different countries (Dalton and Weldon, 2005; Dassonneville, 2012; Söderlund, 2008).

Self-evidently, socio-demographic factors such as gender and levels of education have to be controlled for. Additionally, previous research has pointed out that citizens' attitudes stabilize as they grow older (Alwin and Krosnick, 1991). The same has been found with respect to the stability of vote choices (Dassonneville, 2013; Gomez, 2013). Consequently, we expect to find a negative effect of age on party switching, which would indicate that older voters have more stable party preferences.

\section{Data and methods}

\subsection{Data}

We test the hypotheses outlined above using data from the Comparative Study of Electoral Systems (CSES 2007; 2012). The CSES is a standardized cross-national election survey administered after elections in over fifty countries ${ }^{3}$. Starting with the second CSES module a

\footnotetext{
${ }^{3}$ All the technical and methodological information for the surveys included in the CSES can be found at www.cses.org.
} 
recall question was administered to gauge for voting behavior in the previous election. This allows us to compute the total amount of party switching between elections. Recall questions can be argued to be sub-optimal measures for investigating volatility because they will stimulate false reports of stability (Festinger, 1957). Previous research has indicated that the use of recall questions leads to an underestimation of volatility. The typical reasons for this underestimate include memory problems and the fact that voters tend to - consciously or subconsciously - adjust their previous vote to be in line with their preference (van Der Eijk and Niemöller, 1983; Waldahl and Aardal, 2000). The extent to which respondents correctly recall their previous vote is usually assumed to be correlated to individual-level variables that are linked to party switching (Converse, 1962). The empirical evidence for such systematic correlations, however, is scarce (van Der Eijk and Niemöller, 2008). For the purpose of the current analyses, it is important to observe that the errors in the vote shares of the previous election do not correlate significantly to any of the contextual level variables ${ }^{4}$.

We use a subset of election studies in the CSES that included a recall question (see Appendix I). Additionally, we cross-validated the data by comparing the recalled voting behavior of respondents in the estimation sample with official election results (see Appendix III). Only election samples in which there were no grave biases of the recalls vis-à-vis the actual results were retained for the analyses. ${ }^{5}$ This step considerably reduces the number of elections in our sample and strongly reduces the number of newer democracies included. Obviously, this

\footnotetext{
${ }^{4}$ These analysis are available from the authors on request

${ }^{5}$ We excluded elections in which the results for one or more a parties result diverged by more than 7.5 percentage points compared to the official result and for which a similar bias (more than 5 percentage points) could not be observed for the current election. This way we assure that elections with problematic recall questions are eliminated. Moreover, as in some cases these differences clearly originate in coding errors for parties, we also see this as an indicator for the general reliability of the coding of party-choice for those elections. See Appendix I for details on which elections were retained. More stringent cut-off points were tested and our results proved robust in these cases. Results available from the authors upon request.
} 
limits the generalizability of our findings to established democracies only, but we can confidently say that doing so prevents generalizations based on flawed data.

Aggregate measures of net volatility use election results and thus imply that the changes observed can also be caused by increases or decreases in turnout levels rather than partychanges alone. For investigating the impact of the party system on party switching only, we restrict the sample to those respondents who voted in both the current and the recalled election.

We furthermore restricted the dataset to surveys for parliamentary elections and to elections that were conducted freely according to Freedom House. We excluded presidential elections as in these cases leadership characteristics are much more important elements of electoral choice and so they are less influenced by the party-system variables (Aarts et al., 2011). The absence of questions for the construction of our key independent variables further reduced the number of elections retained somewhat (see Appendix I on which elections were excluded and the reasons for doing so).

Party splits or mergers have the potential to complicate our operationalization of party switching. The disappearance of a party, or the combination of multiple parties, forces a voter to reevaluate the contours of the ideological space. In many cases, however, the new party is very similar to the old one, rendering it debatable if the voter can be considered volatile. To decide on who to label as a 'party-switcher', we looked up the electoral report of all elections in our sample in Electoral Studies, the European Journal of Political Research or West European Politics. Based on this documentation we decided whether a party could be labeled as 'new' or a compilation/splintering of former parties. Extensive information on what changes were considered party switching is provided in Appendix II. 


\subsection{Measurements}

Our models incorporate a number of summary statistics developed in the literature. First, we measure the effective number of electoral parties as proposed by Laakso and Taagepera (1979).

Second, almost all regularly-used indices of polarization are based on the position of the parties on a single left-right continuum (Abedi, 2002; Crepaz, 1990; Lijphart, 1999). Respondents are capable of meaningfully placing different parties on a same left-right issue scale (Budge and McDonald, 2006; Freire, 2008). Furthermore, recent work indicates that voters' placement of parties correlate highly with expert judgments or party placements obtained from political elites (Dalton and McAllister, 2013). Therefore, we are confident that using voters' placement of parties on a left-right scale within CSES is a valid basis for computing different measures of polarization.

Three general groups of polarization indices - that differ slightly in terms of how the concept is operationalized - are present in the literature. Polarization indices of the first type are simply based on parties' left-right placements. The distance between the most extreme left and right parties is then calculated as a measure of polarization (Abedi, 2002; Crepaz, 1990; Indridason, 2011). Even though this measure is argued to be less suitable in multiparty settings, we will use an unweighted measure gauging the distance between the two most extreme parties as a first measure of polarization. A second type of index uses information from all parties and is weighted for their relative strength. As a second measure in our analyses, we replicated such a measure constructed by Dalton (2008) ${ }^{6}$. A third type of indicator incorporates the variance of the electorate and keeps the full amount of information

\footnotetext{
${ }^{6}$ Formula: Polarization $_{\text {Dalton }}=\sqrt{\sum_{i=1}^{n} \quad p_{i}\left(\left(\operatorname{partyLR}_{i}-\text { meanLR }\right) / 5\right)^{2}}$
} 
from all parties. Alvarez and Nagler's (2004) measure of compactness, for example, not only looks at how dispersed the parties are on a left-right scale, but also relates this to the dispersion of the general population ${ }^{7}$. Although the measure was initially developed to look at separate issues, Ezrow (2007) has demonstrated this can also be applied to the general ideological placement of voters and parties. ${ }^{8}$

To verify the robustness of our findings, we perform our analyses with an index from each of these groups separately. All polarization indices include somewhat different information but obviously the three indices used are strongly correlated. ${ }^{9}$ To prevent multicolinearity problems in the analyses we will test the impact of each of the measures separately.

We account for the fact that differences in electoral systems are linked to volatility. The proportionality of an electoral system correlates strongly to the number of parties (Neto and Cox, 1997), therefore most of these claims boil down to the effect of the number of parties. We control for the proportionality of an electoral system, for which a number of different indices have been proposed in the literature (Gallego et al., 2012). In the current analyses, we use the least squares index of disproportionality, as calculated and provided by Gallagher (2013).

To investigate the effect of party identification we use a measure based on the question 'Do you usually think of yourself as close to any particular party?', to which respondents could answer either yes or no. As Thomassen and Rosema (2009) claim, this question wording

\footnotetext{
${ }^{7}$ Formula: Compactness Alvarez^Nagler $=\frac{\sigma_{\text {partiesLR-position }}}{\sum_{i=1}^{n} p_{i} \mid \text { partyLR } R_{i}-\text { meanLR } \mid}$

${ }^{8}$ Note that Ezrow inverses this index to become a measure of dispersion rather than compactness as this is more straightforwardly understood. We will use the original Alvarez \& Nagler formula.

${ }^{9}$ The Pearson correlation coefficient between the unweighted distance measure and the Dalton index is 0.803 , the Pearson correlation coefficient between the unweighted distance measure and Alvarez \& Nagler's measure of compactness is -0.630 and the Pearson correlation coefficient between Alvarez \& Nagler's measure and Dalton's polarization index is -0.838 .
} 
possibly captures a more variable attitude than the original concept of party identification. Given that the effect of identifying with a particular party on volatility is likely very strong, including such a proxy for partisanship is a stringent control when investigating what causes voters to switch parties.

The concept of political sophistication refers to the voters' level of conceptualization and is affected both by the voters' openness to political information and by their capacity to process this information (Campbell et al., 1963; Lachat, 2007; Luskin, 1990). Given that political knowledge is often considered the best single indicator of political sophistication (Lachat, 2007), we rely on political knowledge as measure for political sophistication. Within the framework of the CSES, each election survey contains three political knowledge questions. Adding up the number of correct answers on the three questions gives us for each respondent a political knowledge score between 0 and $3 .{ }^{10}$ In order to further enhance the comparability of this knowledge measure across countries and election samples, we additionally standardized political knowledge by dividing respondents' knowledge score by the electionspecific sample mean (Singh and Thornton, 2013).

We use several related political attitudes to investigate the impact of political disaffection on volatility. Previous research has shown that dissatisfaction with democracy and external efficacy are all linked with electoral volatility (Dalton and Weldon, 2005; Dassonneville, 2012; Söderlund, 2008; Zelle, 1995). Satisfaction with democracy is measured by means of a single item asking respondents 'On the whole, are you very satisfied, fairly satisfied, not very satisfied, or not at all satisfied with the way democracy works in [country]' (reverse coding). For external efficacy, we make use of the items 'who is in power can make a difference' and

\footnotetext{
10 Wrong answers, don't knows and refusals to answer the questions were all treated equally as wrong. For a number of election samples, only one of both items was included in the survey and therefore only one item is included in the efficacy scale. See Appendix I on the elections to which this applies
} 
'who people vote for makes a difference', both asked on a scale ranging between 1 and 5 . Given that these items load strongly on a one-dimensional scale (Eigenvalue: 1.47; Explained variance: $64.31 \%$ ), they were added into a 1 to 5 additive scale of external political efficacy. ${ }^{11}$ Furthermore, we include socio-structural control variables for respondents' age, gender, and whether or not they obtained any kind of college degree.

Missing values on some of the independent variables further reduces the estimation sample to 29,591 individuals in 33 elections. ${ }^{12}$ These elections were held in 18 different countries, most of which can be considered established democracies. Descriptive statistics for the independent variables can be found in Appendix VI.

\subsection{Method}

We investigate the causes of electoral volatility at an aggregate and individual level respectively. For the aggregate-level analyses, the dependent variable is the Pedersen index of net volatility. Given the continuous nature of this measure, we make use of an OLS regression for this analysis.

Our individual-level dependent variable, party switching, is binary; these analyses will take the form of logistic regressions. Furthermore, heterogeneity in the dataset must be taken into account. Voters in a particular electoral context are more alike than voters in different contexts. Because we want to integrate both individual and contextual theories explaining volatility, we use multilevel analysis techniques (Steenbergen and Jones, 2002).

\section{Results}

\footnotetext{
${ }^{11}$ For a number of election samples, only one of both items was included in the survey and therefore only one item is included in the efficacy scale. See Appendix I on the elections to which this applies.

12 When taking into account voters switching to and from abstention as well, the sample size is 33,530 (equally nested in 33 elections).
} 


\subsection{The amount of volatility}

We observe considerable variation in party switching in the sample. As Table 1 makes clear, on average, just less than $30 \%$ of the 29,591 respondents in the analyses (i.e. those that voted twice) report having changed party preferences. The amount of party switching varies considerably between the elections included in these data; for example over $60 \%$ of Irish respondents report switching in the 2007 election. Furthermore, the Dutch electoral context is remarkably unstable, an image that is in line with what aggregate level data on volatility suggest (Dassonneville, 2013). At the other extreme of Table 1 we find very stable elections, such as the Portuguese 2002 election, the British 2005 election and the Spanish 2004 election.

[Table 1 about here]

Reading through Table 1 indicates marked variation in the extent to which respondents in different election samples report switching parties from one election to another. Before investigating whether the relationship between party switching and characteristics of the party system are indeed driven by individual-level mechanisms, it is prudent to assess the degree to which individual-level switching in the dataset and net volatility actually correlate. Figure 1 illustrates a moderate correlation of $0.43(\mathrm{p}<0.05)$ between the proportion of respondents reporting to have switched parties in a particular election sample on the one hand and the Pedersen index ${ }^{13}$ for that same election on the other.

[Figure 1 about here]

\subsection{Pedersen index of net volatility}

\footnotetext{
${ }^{13}$ Own calculation of the Pedersen index for official election results. Pedersen index $=1 / 2 *\left\{\sum_{\mathrm{i}=1}^{\mathrm{n}}\left|\Delta \mathrm{p}_{\mathrm{i}, \mathrm{t}}\right|\right\}$ with $\mathrm{p}_{\mathrm{i}, \mathrm{t}}$ being the vote share of party $\mathrm{i}$ at election $\mathrm{t}$ and $\mathrm{n}$ being the total number of parties. Information on electoral results comes from the European Journal of Political Research, Electoral Studies, West-European Politics and on-line sources (www.parlgov.com; www.parties-and-elections.eu).
} 
As a first step we present an aggregate-level analysis, in line with the model presented in the original Pedersen paper. We investigate the relationship between our measures of the number of parties and systemic polarization, on the one hand, and net volatility - controlling for disproportionality — on the other hand. We present three separate models, drawing from 33 elections in our individual-level sample, in which each measure of polarization discussed above is included.

The effective number of parties is robust to varying polarization measures and points at a positive and significant effect on net volatility across each of the models in Table 2 . The measure of disproportionality and the first two measures of polarization, on the contrary, are not significantly related to net volatility. Only compactness reaches a marginal level of significance, but clearly the ENEP is the more robust predictor of net volatility. ${ }^{14}$ In the original analysis, Pedersen assumed polarization-rather than the number of partiesexacerbates volatility. These results strongly suggest the number of parties is associated with a high degree of net volatility. The evidence is mixed when relating polarization with volatility. Therefore, at the macro-level, there is weak evidence that polarization would be the main contextual variable affecting party switching ${ }^{15}$.

[Table 2 about here]

\subsection{Individual-level volatility}

Pedersen's assumption with regard to polarization was clearly framed in individual terms. Therefore, we next present the results of a multilevel random intercept model using the CSES

\footnotetext{
${ }^{14}$ Standardizing the ENEP and the measure of compactness (in Model III) to both run from 0 to 1 , additionally points out that the impact of ENEP (8.99) is larger than the effect of compactness (-5.43).

15 Pedersen relied on country experts to estimate the number of parties contesting an election in his sample. Since his publication, the Effective Number of Electoral Parties index by Laakso and Taagepera (1979) has become the standard way to measure this variable. The different result we obtain from Pedersen might therefore to some extent also be related to the use of a more fine-grained indicator for this variable. We thank a reviewer for pointing to this fact.
} 
survey data. Given that the dependent variable is binary (respondents either report having switched parties or not), the model takes the form of a logistic regression. Again, we present the results of separate models for each index of polarization.

The results of these analyses lead to different conclusions regarding which systemic factors affect party switching compared to the analysis for net volatility (see Table 3). First, we do not observe a significant effect of the number of parties on respondents' probability to report switching parties. The hypothesis that more parties leads to more volatility is not supported by these data. We do find a negative and significant effect of disproportionality; as an electoral system is more disproportional, voters become less likely to switch parties from one election to another.

According to Pedersen's theoretical framework, more aggregate-level volatility is driven by the reduced ideological distance between parties in more crowded party systems. The results of the analyses presented in Table 3 provide suggestive evidence supporting this assumption. The effect of polarization on switching parties is significant and in expected directions for each of the indicators included: negative for the first two indicators and positive for the indicator of compactness. ${ }^{16}$ Our findings, furthermore, are robust to all three measures of polarization, even the most minimal operationalization - the maximum ideological distance between two parties in an electoral system. Our results show that as a party system is more compact, voters are more likely to switch parties.

[Table 3 about here]

In a next step, we investigate whether the effect of the systemic contextual variables hold when controlling for individual-level variables capturing political sophistication, political disaffection, and socio-demographics.

16 Given the rather small $\mathrm{N}$ at the election level (33), we can safely use less conservative levels of significance 
As clear from the results in Table 4, the effects of the contextual variables on respondents' probability to switch parties are robust with regard to a large set of individual-level predictors. A more disproportional electoral system and the three indicators for polarization are still significantly related to lower probabilities of switching parties. The plots of predicted probabilities for Models I, II, and III from Table 4 are shown in Figure 2 and give some indication of the strength of the effect of polarization. All three indicators increase the probability of switching parties by between 15 and 20 percentage points when moving from one extreme to another. This can be considered a sizable effect for a single contextual variable.

[Table 4 about here]

[Figure 2 about here]

For the individual-level predictors, results are in line with previous research. Older voters are significantly less likely to report switching while there is no significant difference between men and women's probability of switching parties. Furthermore, the higher educated are significantly more likely to report switching compared to respondents without higher education. Second, the term capturing political knowledge squared is negative and significant, hinting at a significant curvilinear effect, with the middle knowledgeable respondents having the highest probability of switching parties. Third, both political efficacy and satisfaction with democracy are significant and negatively related to the probability to switch parties, indicating that political disaffection increases voters' probability to desert the party they voted for in the previous election.

Pedersen's theoretical assumptions all relate to the impact of contextual variables on voters' probability of switching parties. Empirically, however, Pedersen tested this by means of an index of net volatility. As net volatility is affected by the extent to which citizens are 
mobilized or demobilized for particular elections, differences between his results and our findings for party switching could be driven by whether or not abstainers are taken into account. To verify the impact of abstention, we have replicated the analyses with an individual-level indicator of volatility as the dependent variable. Importantly, this indicator considers citizens switching to or from abstention from one election or another as volatile. The results of these analyses are reported in Appendix $\mathrm{V}$ and clarify that for a broad operationalization of volatility, the number of parties - and not polarization-causes instability, which is in line with an aggregate-level analysis of net volatility à la Pedersen. Our main analyses, by contrast, show that polarization has a much larger effect than the number of parties on switching.

Thus far, our analyses have investigated party switching without taking into account party identification. We now model party switching with reference to this strong predictor of vote choice. Doing so is a very stringent test, because it can be assumed that partisanship acts as an intermediary variable between the contextual and individual-level variables. As we demonstrated in Table 5 (see Model I) the direction of the estimated effects holds, but the effects of the polarization indices no longer reach a conventional level of statistical significance when we add closeness to a party to the analyses. ${ }^{17}$ While our initial results indicate that polarization significantly decreases the probability that individual voters will change parties from one election to another, this additional analysis indicates that partisanship acts as a powerful barrier to contextual effects. If one takes into account voters' feelings of closeness to a party, it seems as if this renders the choice set irrelevant. To verify whether this is indeed the case, we add cross-level interaction terms between partisanship and

\footnotetext{
17 We only present model I here without interaction terms and maximum left-right distance as polarization measure, but the results are similar and non-significant for the Dalton measure and compactness. Results available from the authors upon request.
} 
the contextual variables into a model. Models II to V offer indications of significant crosslevel interactions between partisanship and our measures of polarization. To ease the interpretation of these effects, we plotted the estimated impact of compactness (as estimated in Model V) for partisans and nonpartisans separately. As is clear from Figure 3, polarization acts to reduce the strong barrier effect of partisanship on party switching. This is evident from the fact that the difference between partisans and nonpartisans in their probability to switch parties is strongly reduced as the party system is more compact. Even though partisanship is still a significant predictor of party switching in highly compact party systems, an ideologically dense set of choices does reduce the pronounced differences between partisans and nonpartisans that are found in highly polarized settings.

[Table 5 about here]

[Figure 3 about here]

\subsection{Additional robustness checks}

One could claim that investigating the impact of contextual variables on voting behavior ought to be lagged. Given that the indices of disproportionality and the effective number of parties are based on election results, there is a tautological element in explaining voters' behavior in an election by means of indicators that are constructed on the basis of election results. Therefore, as an additional test, we included lagged variables for the least squares index of disproportionality and the effective number of parties. For the polarization measures, by contrast, given that parties' positions are likely to change considerably over a period of multiple years, we assume that respondents' perception of parties' positions immediately after an election are related more strongly to their perceptions before going to vote than the perceptions of parties' positions years before (see Zaller 1992). These models with lagged indicators for disproportionality and the effective number of parties show our results to be 
robust. Both the direction of the estimated effects and their significance levels withstand this test. $^{18}$

\section{Discussion}

Until the present study it was unclear to what extent party-system variables affect the probability that individual voters switch parties between elections. Our aggregate level analysis shows that up to $40 \%$ in the between-election variance in volatility can be explained with three party-system level variables, of which the number of parties seems to matter most. When exploring this with individual level data, however, we see that it is actually the polarization of the party system that increases the likelihood that voters switch between elections. We can now confirm Pedersen's claim — made more than thirty years ago — that it is the polarization of the parties that matters as a mechanism triggering individual voters to switch parties.

For net volatility, we conclude that the ENEP index is not a proxy for polarization as Pedersen assumed. Including both variables in the analysis of the Pedersen index shows that polarization is not the influential variable. Our aggregate-level results show a robust impact of the number of parties on volatility; this is not so with the individual-level data. This discrepancy might be an effect of the compound nature of the aggregate Pedersen index. The index captures party switching, but also changes driven by voters who voted in one election but abstained in the other. Both of these groups might be influenced by different factors in their electoral behavior, with the latter group being more influenced by variables that typically drive turnout. This was confirmed by an additional individual-level analysis where

\footnotetext{
18 Results available from the authors upon request.
} 
we included those switching from/to abstention as volatile. Those results demonstrate that the number of parties to be influential in this case, but not polarization. This has important consequences for the conceptual difference between party switching and volatility. Our analyses show that conclusions about what drives party switching cannot-ipso facto-be generalized to volatility. The main difference is not between levels of aggregation, but between whether or not abstainers are accounted for in the analysis. Therefore, it is important that future research makes a clearer conceptual difference between party-switching and volatility and investigate separately what factors cause voters to switch parties and what factors affect whether or not voters turn out to vote.

Our additional investigation of the influence of party identification on vote-switching confirms its status as a key variable in voter research. Partisanship acts as a powerful barrier to party switching, overruling even the impact of the degree of polarization in the choice set. The significant interaction effects of partisanship and polarization, however, show that the powerful impact of partisanship on partisan stability is strongly reduced when a party system is very compact.

Methodologically, we concede that the use of recall data is not optimal to answer the hypothesis we investigate here. But this also leads us to emphasize that the only way to make important new steps in this very important field is to conduct comparative panel studies in a large group of democracies. We realize that this involves a considerable organizational and funding effort. Several decades after the Columbia and Michigan studies, we still lack the adequate data to answer what seems to be a very elementary question in comparative political science. This seems to signal, therefore, that this is the only way forward. 
Table 1. Degree of party-switching by election

\begin{tabular}{|c|c|c|c|c|}
\hline Election & $\%$ Stable & \% Switching & $\mathrm{N}$ & $\begin{array}{l}\text { Pedersen index } \\
\text { (Official vote } \\
\text { shares) }\end{array}$ \\
\hline Ireland 2007 & $32.27 \%$ & $62.73 \%$ & 330 & 6.1 \\
\hline The Netherlands 2010 & $56.87 \%$ & $43.13 \%$ & 1,491 & 22.5 \\
\hline The Netherlands 2002 & $57.78 \%$ & $42.22 \%$ & 957 & 30.5 \\
\hline New Zealand 2002 & $59.71 \%$ & $40.29 \%$ & 906 & 8.95 \\
\hline Estonia 2011 & $60.80 \%$ & $39.20 \%$ & 375 & 12.95 \\
\hline The Netherlands 2006 & $62.31 \%$ & $37.69 \%$ & 1,674 & 20.0 \\
\hline Norway 2005 & $64.41 \%$ & $35.59 \%$ & 1,450 & 19.2 \\
\hline Sweden 2006 & $64.46 \%$ & $35.54 \%$ & 664 & 15.8 \\
\hline Finland 2011 & $65.04 \%$ & $34.96 \%$ & 798 & 15.0 \\
\hline Sweden 2002 & $65.05 \%$ & $34.95 \%$ & 658 & 14.4 \\
\hline Iceland 2009 & $66.48 \%$ & $33.52 \%$ & 698 & 21.3 \\
\hline Norway 2001 & $68.12 \%$ & $31.88 \%$ & 1,418 & 16.1 \\
\hline Slovenia 2004 & $68.45 \%$ & $31.55 \%$ & 355 & 21.4 \\
\hline Denmark 2007 & $69.86 \%$ & $30.14 \%$ & 949 & 10.0 \\
\hline Portugal 2005 & $70.29 \%$ & $29.74 \%$ & 1,476 & 11.3 \\
\hline Germany 2005 & $70.44 \%$ & $29.56 \%$ & 866 & 8.1 \\
\hline Norway 2009 & $70.54 \%$ & $29.46 \%$ & 1,334 & 6.6 \\
\hline New Zealand 2008 & $70.84 \%$ & $29.16 \%$ & 535 & 9.6 \\
\hline Australia 2007 & $71.90 \%$ & $28.10 \%$ & 1,025 & 6.8 \\
\hline Canada 2008 & $72.84 \%$ & $27.16 \%$ & 832 & 4.4 \\
\hline Iceland 2007 & $74.22 \%$ & $25.78 \%$ & 896 & 11.8 \\
\hline Switzerland 2007 & $74.57 \%$ & $25.43 \%$ & 1,152 & 6.8 \\
\hline Czech Republic 2002 & $75.02 \%$ & $24.94 \%$ & 425 & 11.5 \\
\hline Australia 2004 & $75.93 \%$ & $24.07 \%$ & 1,259 & 7.5 \\
\hline Germany 2002 & $76.00 \%$ & $24.00 \%$ & 1,521 & 6.5 \\
\hline Germany 2009 & $76.32 \%$ & $23.68 \%$ & 1,077 & 12.9 \\
\hline Finland 2007 & $77.03 \%$ & $22.97 \%$ & 788 & 6.7 \\
\hline Switzerland 2003 & $78.22 \%$ & $21.78 \%$ & 707 & 7.9 \\
\hline Finland 2003 & $79.41 \%$ & $20.59 \%$ & 680 & 6.3 \\
\hline Greece 2009 & $83.87 \%$ & $16.13 \%$ & 496 & 5.7 \\
\hline Portugal 2002 & $85.44 \%$ & $14.56 \%$ & 618 & 8.4 \\
\hline Great Britain 2005 & $85.74 \%$ & $14.26 \%$ & 512 & 6.2 \\
\hline Spain 2004 & $89.39 \%$ & $10.61 \%$ & 669 & 10.2 \\
\hline Total & $70.12 \%$ & $29.88 \%$ & 29,591 & \\
\hline
\end{tabular}

Data: CSES Module 2 and 3. 
Figure 1. Comparison of individual-level party-switching (CSES) and net-volatility (Pedersen index)

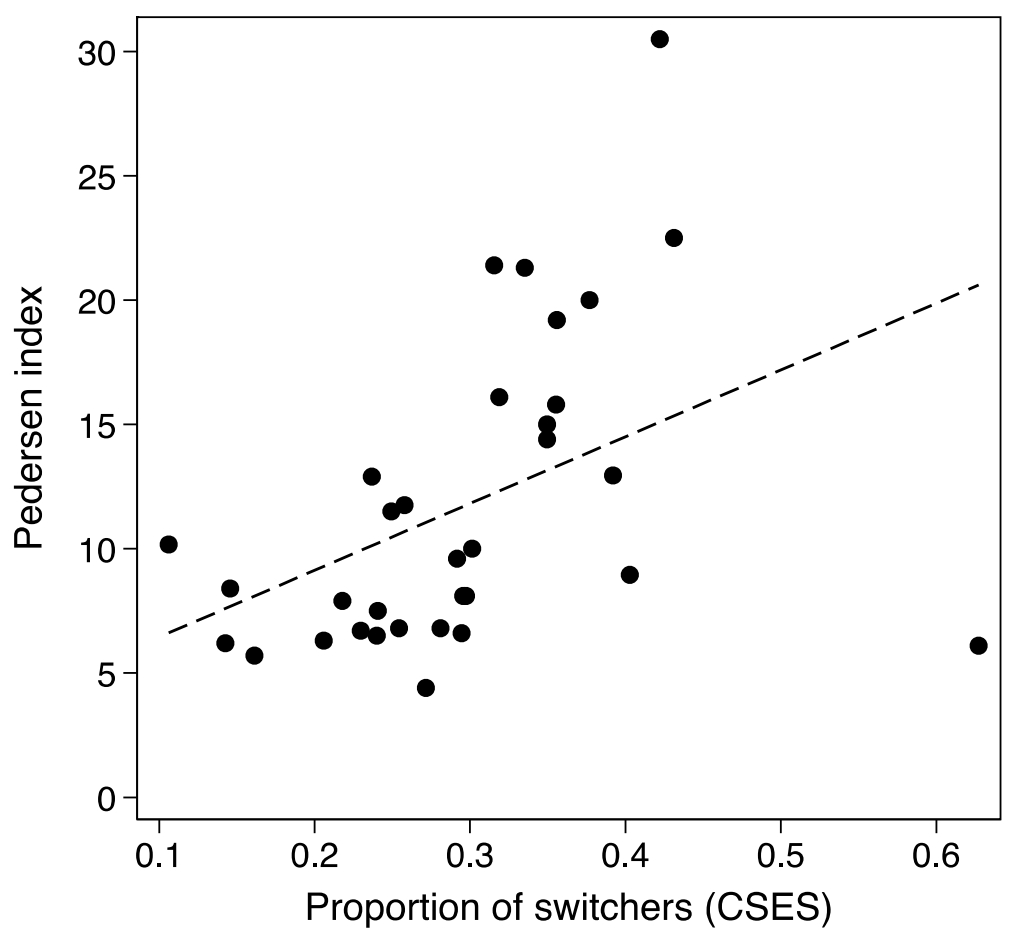


Table 2. Explaining aggregate level volatility

\begin{tabular}{lccc}
\hline \hline & Model I & Model II & Model III \\
& $\mathrm{b}$ & $\mathrm{b}$ & $\mathrm{b}$ \\
& $(\mathrm{s} . \mathrm{e})$. & $(\mathrm{s} . \mathrm{e})$. & 8.584 \\
\hline Intercept & 2.041 & -3.138 & $(5.548)$ \\
& $(5.334)$ & $(5.073)$ & -0.232 \\
$\mathrm{~L}_{\mathrm{S}}$ & -0.409 & -0.261 & $(0.267)$ \\
& $(0.293)$ & $(0.287)$ & $2.264^{*}$ \\
ENEP & $2.263^{+}$ & $2.301^{*}$ & $(1.033)$ \\
& $(1.093)$ & $(1.052)$ & \\
Max. Left-right distance & 0.187 & & \\
& $(0.589)$ & & \\
Polarization & & 1.477 & $-4.484^{+}$ \\
& & $(1.304)$ & $(2.361)$ \\
Compactness & & & 33 \\
$\mathrm{~N}$ & 33 & 33 & 0.385 \\
$\mathrm{R}^{2}$ & 0.348 & 0.367 & \\
\hline \hline
\end{tabular}

Data: Own calculations of the Pedersen index of net volatility; CSES modules 2 and 3. Standard errors are robust for 19 country clusters. Significance levels: ${ }^{+} \mathrm{p}<0.1 ; * \mathrm{p}<0.05 ; * * \mathrm{p}<0.01$. 
Table 3. Explaining individual-level party-switching (contextual predictors)

\begin{tabular}{|c|c|c|c|c|c|c|}
\hline & \multicolumn{2}{|c|}{ Model I } & \multicolumn{2}{|c|}{ Model II } & \multicolumn{2}{|c|}{ Model III } \\
\hline & Coef. & (s.e.) & Coef. & (s.e.) & Coef. & (s.e.) \\
\hline \multicolumn{7}{|l|}{ Individual level } \\
\hline Intercept & -0.469 & $(0.614)$ & -0.256 & $(0.720)$ & $-1.876^{* *}$ & $(0.555)$ \\
\hline \multicolumn{7}{|l|}{ Contextual variables } \\
\hline $\mathrm{L}_{\mathrm{s}}$ & -0.063 & $(0.031)$ & -0.067 & $(0.033)$ & $-0.067 *$ & $(0.031)$ \\
\hline ENEP & 0.084 & $(0.080)$ & 0.088 & $(0.080)$ & 0.094 & $(0.078)$ \\
\hline Max. left-right distance & $-0.106^{+}$ & $(0.060)$ & & & & \\
\hline Polarization & & & $-0.215^{+}$ & $(0.127)$ & & \\
\hline Compactness & & & & & $0.577 *$ & $(0.277)$ \\
\hline \multicolumn{7}{|l|}{ Model fit statistics } \\
\hline $\mathrm{N}$ individuals & \multicolumn{2}{|l|}{29,591} & \multicolumn{2}{|l|}{29,591} & \multicolumn{2}{|l|}{29,591} \\
\hline $\mathrm{N}$ elections & \multicolumn{2}{|l|}{33} & \multicolumn{2}{|l|}{33} & \multicolumn{2}{|l|}{33} \\
\hline Elections $\sigma^{2}$ & \multicolumn{2}{|c|}{$0.173(0.045)$} & \multicolumn{2}{|c|}{$0.174(0.045)$} & \multicolumn{2}{|c|}{$0.167(0.044)$} \\
\hline Rho & \multicolumn{2}{|l|}{0.050} & \multicolumn{2}{|l|}{0.050} & \multicolumn{2}{|l|}{0.048} \\
\hline
\end{tabular}

Data: CSES modules 2 and 3. Null-model: Rho $=0.066$. Coefficients and standard errors of multilevel logit models in Stata via xtmelogit-command. Significance levels: ${ }^{+} \mathrm{p}<0.1 ; * \mathrm{p}<0.5 ; * * \mathrm{p}<0.01 ; * * * \mathrm{p}<0.001$. 
Table 4. Explaining individual-level party-switching (contextual and individual predictors)

\begin{tabular}{|c|c|c|c|c|c|c|}
\hline & \multicolumn{2}{|l|}{ Model I } & \multicolumn{2}{|l|}{ Model II } & \multicolumn{2}{|l|}{ Model III } \\
\hline & Coef. & (s.e.) & Coef. & (s.e.) & Coef. & (s.e.) \\
\hline \multicolumn{7}{|l|}{ Individual level } \\
\hline Intercept & $1.244^{+}$ & $(0.658)$ & $1.500^{+}$ & $(0.767)$ & -0.161 & $(0.598)$ \\
\hline Age & $-0.017 * * *$ & $(0.001)$ & $-0.017 * * *$ & $(0.001)$ & $-0.017 * * *$ & $(0.001)$ \\
\hline Female & 0.016 & $(0.027)$ & 0.016 & $(0.027)$ & 0.016 & $(0.027)$ \\
\hline College education & $0.076^{*}$ & $(0.030)$ & $0.076^{*}$ & $(0.030)$ & $0.076^{*}$ & $(0.030)$ \\
\hline Political knowledge & 0.065 & $(0.062)$ & 0.065 & $(0.062)$ & 0.064 & $(0.062)$ \\
\hline Political knowledge ${ }^{2}$ & $-0.067 *$ & $(0.027)$ & $-0.067 *$ & $(0.027)$ & $-0.067 *$ & $(0.027)$ \\
\hline Efficacy & $-0.149 * * *$ & $(0.014)$ & $-0.149 * * *$ & $(0.014)$ & $-0.149 * * *$ & $(0.014)$ \\
\hline $\begin{array}{l}\text { Satisfaction with } \\
\text { democracy }\end{array}$ & $-0.164 * * *$ & $(0.016)$ & $-0.164 * * *$ & $(0.016)$ & $-0.164 * * *$ & $(0.016)$ \\
\hline \multicolumn{7}{|l|}{ Contextual variables } \\
\hline $\mathrm{L}_{\mathrm{s}}$ & $-0.061^{+}$ & $(0.033)$ & $-0.067^{+}$ & $(0.035)$ & $-0.065^{*}$ & $(0.033)$ \\
\hline ENEP & 0.118 & $(0.085)$ & 0.122 & $(0.084)$ & 0.129 & $(0.083)$ \\
\hline Max. left-right distance & $-0.106^{+}$ & $(0.064)$ & & & & \\
\hline Polarization & & & $-0.226^{+}$ & $(0.135)$ & & \\
\hline Compactness & & & & & $0.570^{+}$ & $(0.295)$ \\
\hline \multicolumn{7}{|l|}{ Model fit statistics } \\
\hline $\mathrm{N}$ individuals & 29,591 & & 29,591 & & 29,591 & \\
\hline $\mathrm{N}$ elections & 33 & & 33 & & 33 & \\
\hline Elections $\sigma^{2}$ & $0.196(0.05$ & & $0.196(0.0$ & & $0.191(0.0$ & \\
\hline Rho & 0.056 & & 0.056 & & 0.055 & \\
\hline
\end{tabular}

Data: CSES modules 2 and 3. Null-model: Rho $=0.066$. Coefficients and standard errors of multilevel logit models in Stata via xtmelogit-command. Significance levels: ${ }^{+} \mathrm{p}<0.1 ;{ }^{*} \mathrm{p}<0.5 ; * * \mathrm{p}<0.01 ; * * * \mathrm{p}<0.001$. 
Figure 2. Estimated effect and 90\%-confidence intervals of polarization measures on party switching
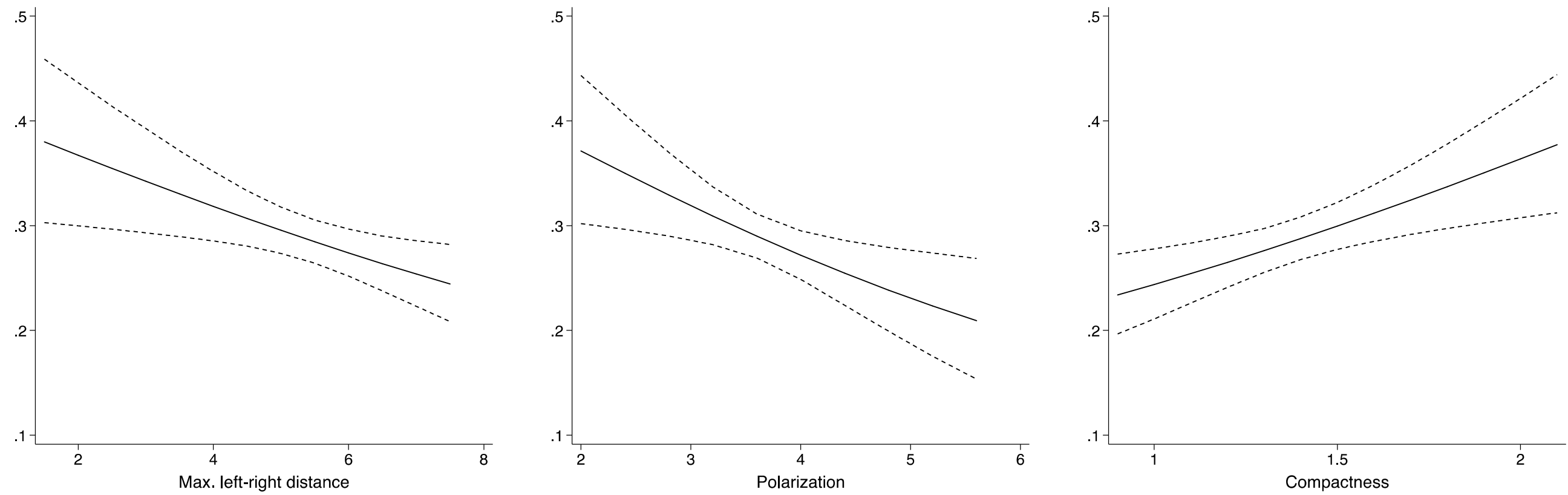

Estimates based on 10,000 simulated observations based on Model I, II and III in Table 4 respectively. 
Figure 3. Estimated effect and 90\%-confidence intervals of compactness on party switching by partisanship.

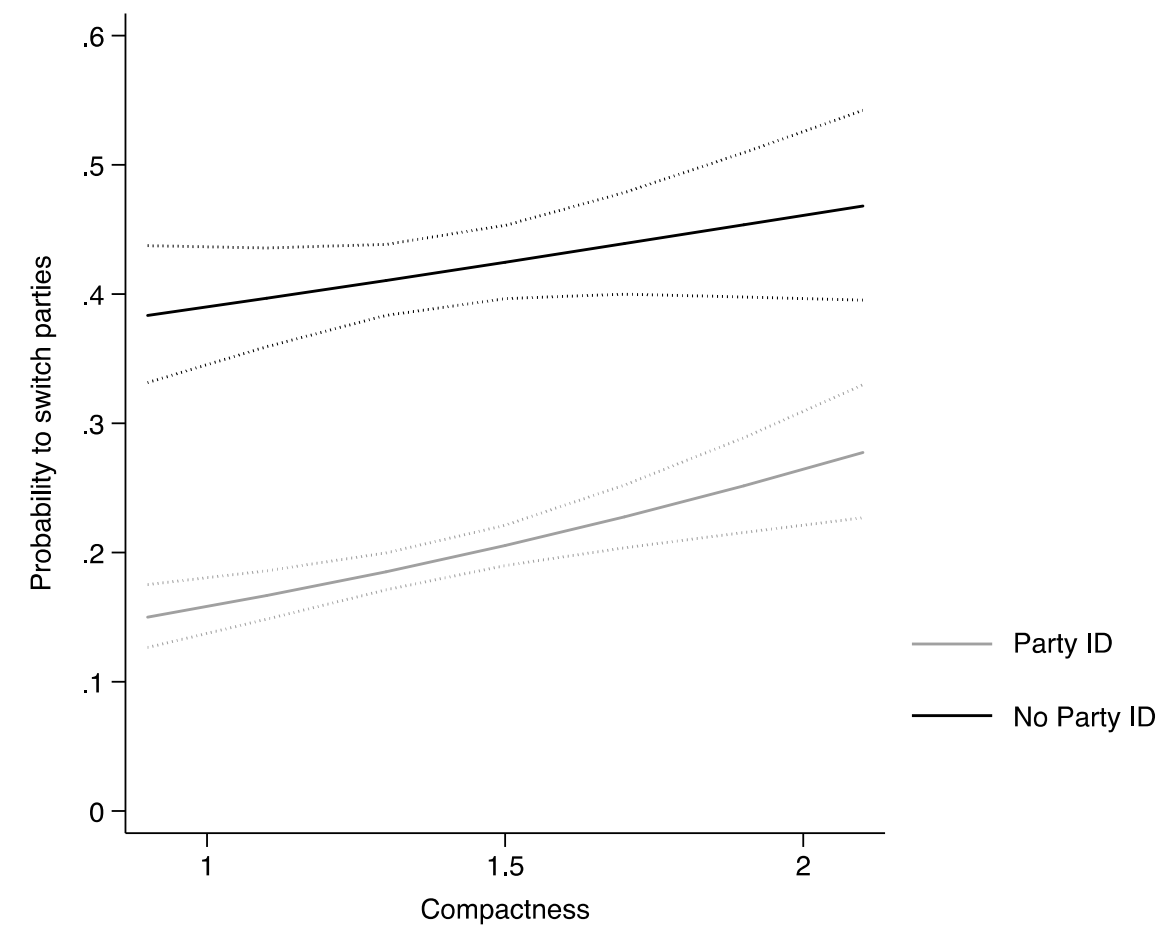

Estimates based on 10,000 simulated observations based on Model V in Table 5. 
Table 5. Explaining individual-level switching (contextual and individual predictors) - interactions of polarization with party ID

\begin{tabular}{|c|c|c|c|c|c|c|c|c|c|c|}
\hline & \multicolumn{2}{|l|}{ Model I } & \multicolumn{2}{|l|}{ Model II } & \multicolumn{2}{|l|}{ Model III } & \multicolumn{2}{|l|}{ Model IV } & \multicolumn{2}{|l|}{ Model V } \\
\hline & Coef. & (s.e.) & Coef. & (s.e.) & Coef. & (s.e.) & Coef. & (s.e.) & Coef. & (s.e.) \\
\hline \multicolumn{11}{|l|}{ Individual level } \\
\hline Intercept & $1.112^{+}$ & 0.001 & 1.069 & $(0.666)$ & 1.028 & $(0.660)$ & 1.050 & $(0.774)$ & 0.519 & $(0.601)$ \\
\hline Age & $-0.014 * * *$ & $(0.001)$ & $-0.014 * * *$ & $(0.001)$ & $-0.014 * * *$ & $(0.001)$ & $-0.014 * * *$ & $(0.001)$ & $-0.014 * * *$ & $(0.001)$ \\
\hline Female & -0.002 & $(0.027)$ & -0.002 & $(0.027)$ & -0.002 & $(0.027)$ & -0.002 & $(0.027)$ & $-0.002 * *$ & $(0.027)$ \\
\hline College education & $0.089 * *$ & $(0.031)$ & $0.089 * *$ & $(0.031)$ & $0.088 * *$ & $(0.031)$ & $0.088 * *$ & $(0.031)$ & $0.088 * *$ & $(0.031)$ \\
\hline Political knowledge & 0.091 & $(0.064)$ & 0.091 & $(0.064)$ & 0.091 & $(0.064)$ & 0.091 & $(0.064)$ & 0.091 & $(0.064)$ \\
\hline Political knowledge ${ }^{2}$ & $-0.062 *$ & $(0.028)$ & $-0.062 *$ & $(0.028)$ & $-0.062 *$ & $(0.028)$ & $-0.062 *$ & $(0.028)$ & $-0.062 *$ & $(0.028)$ \\
\hline Efficacy & $-0.067 * * *$ & $(0.014)$ & $-0.067 * * *$ & $(0.014)$ & $-0.067 * * *$ & $(0.014)$ & $-0.067 * * *$ & $(0.014)$ & $-0.066 * * *$ & $(0.014)$ \\
\hline Satisfaction with democracy & $-0.144 * * *$ & $(0.017)$ & $-0.145^{* * *}$ & $(0.017)$ & $-0.145 * * *$ & $(0.017)$ & $-0.145^{* * *}$ & $(0.017)$ & $-0.145 * * *$ & $(0.017)$ \\
\hline Close to a party & $-1.111 * * *$ & $(0.083)$ & $-0.884 * * *$ & $(0.208)$ & $-0.710 * * *$ & $(0.189)$ & $-0.519 *$ & $(0.262)$ & $-1.624 * * *$ & $(0.220)$ \\
\hline \multicolumn{11}{|l|}{ Contextual variables } \\
\hline $\mathrm{L}_{\mathrm{s}}$ & -0.050 & $(0.034)$ & -0.049 & $(0.033)$ & -0.049 & $(0.033)$ & -0.049 & $(0.035)$ & -0.054 & $(0.033)$ \\
\hline Close to a party*Ls & 0.006 & $(0.017)$ & & & & & & & & \\
\hline ENEP & 0.068 & $(0.085)$ & 0.076 & $(0.085)$ & 0.069 & $(0.085)$ & 0.071 & $(0.084)$ & 0.071 & $(0.083)$ \\
\hline Close to a party*ENEP & & & -0.043 & $(0.043)$ & & & & & & \\
\hline Max. Left-right distance & -0.049 & $(0.065)$ & -0.050 & $(0.065)$ & -0.035 & $(0.064)$ & & & & \\
\hline $\begin{array}{l}\text { Close to a party*Max. Left-right } \\
\text { distance }\end{array}$ & & & & & $-0.070^{*}$ & $(0.034)$ & & & & \\
\hline Polarization & & & & & & & -0.059 & $(0.137)$ & & \\
\hline Close to a party*Polarization & & & & & & & $-0.156^{*}$ & $(0.071)$ & & \\
\hline Compactness & & & & & & & & & 0.236 & $(0.298)$ \\
\hline Close to a party*Compactness & & & & & & & & & $0.383^{*}$ & $(0.154)$ \\
\hline \multicolumn{11}{|l|}{ Model fit statistics } \\
\hline $\mathrm{N}$ individuals & 29,591 & & 29,591 & & 29,591 & & 29,591 & & 29,591 & \\
\hline $\mathrm{N}$ elections & 33 & & 33 & & 33 & & 33 & & 33 & \\
\hline Elections $\sigma^{2}$ & $0.195(0.052)$ & & $0.194(0.052$ & & $0.191(0.051)$ & & $0.191(0.051)$ & & $0.185(0.050)$ & \\
\hline Close to a party $\sigma^{2}$ & $0.049(0.018)$ & & $0.045(0.018$ & & $0.041(0.016)$ & & $0.039(0.016$ & & $0.034(0.015)$ & \\
\hline Rho & 0.069 & & 0.068 & & 0.066 & & 0.065 & & 0.063 & \\
\hline
\end{tabular}

Data: CSES modules 2 and 3. Null-model: Rho=0.066. Coefficients and standard errors of multilevel logit models in Stata via xtmelogit-command. Significance levels: ${ }^{+}$ $\mathrm{p}<0.1 ; * \mathrm{p}<0.5 ; * * \mathrm{p}<0.01 ; * * * \mathrm{p}<0.001$. 


\section{References}

Aarts K, Blais A and Schmitt H (2011) Political Leaders and Democratic Elections. Oxford: Oxford University Press.

Abedi A (2002) Challenges to established parties : The effects of party system features on the electoral fortunes of anti-political-establishment parties. 41(4), 551-583.

Alvarez RM and Nagler J (2004) Party System Compactness: Measurement and Consequences. Political Analysis, 12(1), 46-62.

Alwin DF and Krosnick JA (1991) Aging, Cohorts, and the Stability of Sociopolitical Orientations Over the Life Span. American Journal of Sociology, 97(1), 169-195.

Bardi L and Mair P (2008) The Parameters of Party Systems. Party Politics, 14(2), 147-166.

Bartolini S and Mair P (1990) Identity, Competition and Electoral Availability. The Stability of European Electorates 1885-1985. Cambridge: Cambridge University Press.

Berelson BR, Lazarsfeld PF and McPhee WN (1963) Voting: A Study of Opinion Formation in a Presidential Campaign. Chicago: University of Chicago Press.

Blais A and Gschwend T (2010) Strategic Defection Across Elections, Parties and Voters. In: Dalton RJ and Anderson CJ (eds), Citizens, Context and Choice. How Context Shapes Citizens' Electoral Choices, Oxford: Oxford University Press, pp. 176-193.

Blondel J (1968) Party Systems and Patterns of Government in Western Democracies. Canadian Journal of Political Science, 1(2), 180-203.

Budge I and McDonald MD (2006) Choices Parties Define: Policy Alternatives in Representative Elections, 17 Countries 1945-1998. Party Politics, 12(4), 451-466.

Campbell A, Converse PE, Miller WE, et al. (1963) The American Voter. New York: John Wiley \& Sons.

Crepaz MML (1990) The impact of party polarization and postmaterialism on voter turnout. A comparative study of 16 industrial democracies. European Journal of Political Research, 18(2), 183-205.

Crewe I and Denver D (1985) Electoral Change in Western Democracies: Patterns and Sources of Electoral Volatility. London: Croom Helm.

Curini L and Hino A (2012) Missing Links in Party-System Polarization: How Institutions and Voters Matter. The Journal of Politics, 74(2), 460-473, Available from: http://www.journals.cambridge.org/abstract_S0022381611001721 (accessed 11 January 2013).

Dalton RJ (2008) The Quantity and the Quality of Party Systems: Party System Polarization, Its Measurement, and Its Consequences. Comparative Political Studies, 41, 899-920. 
Dalton RJ and Anderson CJ (2011) Citizens, Context \& Choice. In: Dalton RJ and Anderson CJ (eds), Citizens, Context and Choice. How Context Shapes Citizens' Electoral Choices, Oxford: Oxford University Press, pp. 3-30.

Dalton RJ and McAllister I (2013) Why Parties Change - Or Do They? Citizen Perceptions of the Partisan Landscape. Paper presented at the annual meeting of the American Political Science Association, Chicago, 28 August-1 September.

Dalton RJ and Weldon S (2005) Public images of political parties: A necessary evil? West European Politics, 28(5), 931-951.

Dalton RJ, Mcallister I and Wattenberg MP (2002) The Consequences of Partisan Dealignment. In: Parties without Partisans. Political Change in Advanced Industrial Democracies, Oxford: Oxford University Press, pp. 37-63.

Dassonneville R (2012) Electoral Volatility, Political Sophistication, Trust and Efficacy. A Study on Changes in Voter Preferences during the Belgian Regional Elections of 2009. Acta Politica, 47(1), 18-41.

Dassonneville R (2013) Questioning Generational Replacement. An Age, Period and Cohort Analysis of Electoral Volatility in the Netherlands, 1971-2010. Electoral Studies, 32, 37-47.

Dassonneville R and Dejaeghere Y (2014) Bridging the Ideological Space. A Cross-National Analysis of the Distance of Party Switching. European Journal of Political Research.

Deegan-Krause K and Enyedi Z (2010) Agency and the Structure of Party Competition: Alignment, Stability and the Role of Political Elites. West European Politics, 33(3), 686-710.

Downs A (1957) An Economic Theory of Democracy. New York: Harper \& Row.

Epperly B (2011) Institutions and Legacies: Electoral Volatility in the Postcommunist World. Comparative Political Studies, 44(7), 829-853.

Ezrow L (2007) The Variance Matters : How Party Systems Represent the Preference of Voters. The Journal of Politics, 69(1), 182-192.

Ezrow L (2008) Parties' Policy Programmes and the Dog that Didn't Bark: No Evidence that Proportional Systems Promote Extreme Party Positioning. British Journal of Political Science, 38(3), 479-497.

Festinger L (1957) A Theory of Cognitive Dissonance. Stanford: Stanford University Press.

Freire A (2008) Party Polarization and Citizens' Left--Right Orientations. Party Politics, 14(2), 189209.

Gallagher M (2013) Electoral Systems Webpage. Available from: http://www.tcd.ie/Political_Science/staff/michael_gallagher/ElSystems/\#. 
Gallego A, Rico G and Anduiza E (2012) Disproportionality and voter turnout in new and old democracies. Electoral Studies, Elsevier Ltd, 31(1), 159-169.

Gomez R (2013) All That You Can(not) Leave Behind: Habituation and Vote Loyalty in the Netherlands. Journal of Elections, Public Opinion \& Parties, 23(2), 134-153.

Hazan R (1997) Centre Parties: Polarization and Competition in European Parliamentary Democracies. London: Pinter.

Indridason IH (2011) Coalition Formation and Polarisation. European Journal of Political Research, $50,689-718$.

Key VO (1966) The Responsible Electorate: Rationality in Presidential Voting 1936-1960. Cambridge (MA): Harvard University Press.

Kuhn U (2009) Stability and Change in Party Preference. Swiss Political Science Review, 15(3), $463-$ 494.

Laakso M and Taagepera R (1979) The "Effective" Number of Parties: A Measure with Application to West Europe. Comparative Political Studies, 12(1), 3-27.

Lachat R (2007) A Heterogeneous Electorate. Political Sophistication, Predisposition Strength and the Voting Decision Process. Baden-Baden: Nomos.

Lane J and Ersson S (2007) Party System Instability in Europe : Persistent Differences in Volatility between West and East? Democratization, 14(1), 92-110.

Lazarsfeld PF, Berelson BR and Gaudet H (1949) The people's choice : how the voter makes up his mind in a presidential campaign. New York: Columbia University Press.

Lijphart A (1999) Patterns of Democracy: Government Forms and Performance in Thirty-Six Countries. New Haven: Yale University Press.

Lipset S and Rokkan S (1967) Party Systems and Voter Alignments: Cross-National Perspectives. New York: Free Press.

Luskin RC (1990) Explaining Political Sophistication. Political Behavior, 12(4), 331-361.

Mainwaring S and Zoco E (2007) Political Sequences and the Stabilization of Interparty Competition: Electoral Volatility in Old and New Democracies. Party Politics, 13(2), 155-178.

Mair P (1995) Political parties, popular legitimacy and public privilege. West European Politics, 18(3), 40-57.

Pedersen MN (1979) The Dynamics of European Party Systems: Changing Patterns of Electoral Volatility. European Journal of Political Research, 7(1), 1-26. 
Roberts KM and Wibbels E (1999) Party Systems and Electoral Volatility in Latin America: A Test of Economic , Institutional , and Structural Explanations. The American Political Science Review, 93(3), 575-590.

Rose R and Mcallister I (1986) Voters Begin to Choose. From Closed-Class to Open Elections in Europe. London: Sage.

Sartori G (2005) Parties and Party Systems. A Framework for Analysis. Colchester: ECPR Press.

Singh S and Thornton J (2013) Compulsory Voting and the Dynamics of Party Identification. European Journal of Political Research, 52, 188-211.

Söderlund P (2008) Retrospective Voting and Electoral Volatility: A Nordic Perspective. Scandinavian Political Studies, 31(2), 217-240.

Steenbergen MR and Jones BS (2002) Modeling Multilevel Data Structures. American Journal of Political Science, 46(1), 218-237.

Tavits M (2005) The Development of Stable Party Support: Electoral Dynamics in Post-Communist Europe. American Journal of Political Science, 49(2), 283-298.

Thomassen J and Rosema M (2009) Party Identification Revisited. In: Bartle J and Bellucci P (eds), Political Parties and Partisanship: Social Identity and Individual Attitudes, London: Routledge.

Toka G (1998) Party Appeals and Voter Loyalty in New Democracies. Political Studies, 46(3), 589610.

Van Der Eijk C and Niemöller B (1983) Electoral Change in the Netherlands. Amsterdam: CT Press.

Van Der Eijk C and Niemöller B (2008) Recall Accuracy and its Determinants. In: Arzheimer K and Evans J (eds), Electoral Behavior. Volume 4: Debates and Methodology, Los Angeles: Sage, pp. 232-280.

Vegetti F (2014) From political conflict to partisan evaluations: How citizens assess party ideology and competence in polarized elections. Electoral Studies, Elsevier Ltd, 35, 230-241.

Waldahl R and Aardal B (2000) The Accuracy of Recalled Previous Voting: Evidence from Norwegian Election Study Panels. Scandinavian Political Studies, 23(4), 373-389.

Ware A (1996) Political Parties and Party Systems. Oxford: Oxford University Press.

Zelle C (1995) Social dealignment versus political frustration: Contrasting explanations of the floating vote in Germany. European Journal of Political Research, 27(3), 319-345. 